\section{Size at birth and height in early adolescence: a prospective birth cohort study}

\author{
Tamanho ao nascer e altura no início da \\ adolescência: um estudo de coorte prospectivo
}

\section{${ }^{1}$ Programa de Pós-Graduação em Epidemiologia, Universi- dade Federal de Pelotas, Pelotas, Brasil. \\ Correspondence C. L. P. Araújo Programa de Pós-Graduação em Epidemiologia, Universidade Federal de Pelotas. \\ Av. Duque de Caxias 250, 3o piso, Pelotas, $R S$ 96030-002, Brasil. cora.araujo@terra.com.br}

\section{Abstract}

The aim of this study was to evaluate the association between size at birth (birthweight and birth length) and height in early adolescence in a prospective birth cohort study in Pelotas, Rio Grande do Sul, Brazil. Interviews were carried out in 1993, including measurements of birthweight and length, and in 2004-2005, including measurements of weight and height. This analysis includes 4,452 individuals, with a mean age of 11.3 years (standard deviation $-S D=0.3$ ), representing a follow-up rate of $87.5 \%$. Mean height at 11 years was $145.8 \mathrm{~cm}(S D=7.9)$, or $144.9 \mathrm{~cm}$ $(S D=7.7)$ in boys and $146.8 \mathrm{~cm}(S D=7.9)$ in girls. Birthweight and birth length were positively associated with height in early adolescence in the crude analysis, but after adjustment for confounding and for each other, only the effect of birth length was still significant. A one z-score increase in birth length was associated with a 1.63 $\mathrm{cm}$ increase in height at 11 years. The present study shows that birth length is a strong predictor of later height, while the effect of birth weight disappears after adjustment for birth length.

Body Height; Birth Weight; Gestational Age; Prospective Studies; Longitudinal Studies
Cora L. P. Araújo ${ }^{1}$

Pedro C. Hallal 1

Gisele A. Nader 1

Ana Maria B. Menezes 1

Cesar G. Victora 1

\section{Introduction}

The evidence linking nutritional status to subsequent risk of morbidity and mortality at all ages is well-established 1,2. Evaluating the nutritional status of children and adolescents is particularly relevant, given the possibility of carrying out early interventions against under- or over-nutrition, both of which are important public health problems ${ }^{3}$. Studies on the epidemiology of nutritional status have focused much more attention on weight and body mass index than on height. However, height alone has been associated with several outcomes and all-cause mortality ${ }^{4}$. Particularly in terms of respiratory and coronary heart disease, shorter subjects are more likely to die prematurely than taller ones 5,6.

Prevalence of stunting in Brazilian children is still relatively high 7 , although marked declines have been observed for wasting and underweight 8,9 . Studying linear growth among children may provide clues on the persistence of adverse conditions limiting the achievement of biological growth potential 10,11. Size at birth reflects intrauterine growth, and it has been suggested that it may affect later height ${ }^{12}$. In addition, post-natal growth has also been related to attained size 13,14 .

Relatively few studies have explored the effects of early size on height in later life. In Brazil, Drachler et al. 10 reported a positive association between birthweight and stature at 12-59 
months. In a Polish study 11, birthweight for gestational age was positively associated with height at 14 years. In a study of Danish adults, Sorensen et al. 12 found that although both birthweight and birth length presented a crude positive association with adult height, after adjustment for each other, the effect of birth length was much stronger.

In this paper, we evaluate the association between size at birth (birthweight and birth length) and height in early adolescence in a cohort of over 4,000 Brazilian children followed prospectively since birth.

\section{Materials and methods}

Pelotas is a city with 323,000 inhabitants located in the extreme South of Brazil; 93\% living in urban areas. In 1993, all hospitals were monitored daily, and mothers of all newborns were invited to join a prospective study (more than $99 \%$ of all deliveries in the city in 1993 took place in these hospitals) 15. Mothers were interviewed shortly after delivery on demographic, socioeconomic, and health-related variables. Newborns were weighed by the study team with pediatric scales accurate to $10 \mathrm{~g}$, and were measured with stadiometers accurate to $1 \mathrm{~mm}$. Gestational age in weeks was estimated based on physical examination using the Dubowitz method 16. Birthweight and birth length were converted into z-scores using the Centers for Disease Control and Prevention (CDC) reference curve 17 (other available curves start at $48 \mathrm{~cm}$ four birth length, and would have excluded almost a fourth of our sample). Children were classified as having small (SGA) or adequate (AGA) birthweight for gestational age according to the $10^{\text {th }}$ centile of Kramer references 18 .

In 2004-2005, a search was conducted for all the cohort members using two citywide censuses. The approximately 100 schools and all 100,000 households in the city were visited in order to help locate subjects born in 1993. Those identified were linked to the cohort database. Individuals who had not been identified through these strategies (approximately 15\% of the cohort members) were searched for in their previously available addresses and by asking other cohort children. Deaths between 1993 and 2005 were monitored. Further details of the strategies used to trace cohort members have been described elsewhere 19 . Height at 11 years was measured in the homes using a portable stadiometer accurate to $1 \mathrm{~mm}$. Weight was measured with an electronic scale (SECA, Australia), accurate to 100g. For girls, age at menarche was investigated through maternal recall.
Interviewers in the 2004-2005 visit were trained for two weeks in the application of a standardized and pre-tested questionnaire, and in the measurement of weight and height. Standardization sessions were carried out before the start of data collection and every month during the fieldwork. Reported measurement errors from the National Center for Health Statistics (NCHS) 20 were used as the maximum acceptable limits in these standardization sessions. Approximately $10 \%$ of the interviewees were re-visited by a field supervisor one or two weeks after the original interview, and a short version of the entire questionnaire was applied for quality control.

Double data entry was carried out in all phases of the birth cohort study. Descriptive analyses included calculation of means and standard deviations for quantitative variables, and proportions and $95 \%$ confidence intervals $(95 \% \mathrm{CI})$ for categorical outcomes. Mean height at 11 years was included as the outcome in simple linear regression models, using continuous birthweight and birth length as independent variables. Pearson correlation coefficients between height at 11 years and independent variables were also calculated. Analyses were stratified according to birthweight for gestational age. In the multivariate analyses, multiple linear regression models were used. Confounding variables included in the analyses were maternal weight and height at the beginning of the pregnancy, family income, maternal smoking during pregnancy, parity, maternal schooling, maternal age, and child's sex. The outcome variable (height at 11 years) presented normal distribution, as did birth weight and length, expressed as continuous variables. Linear regressions assumptions - normal distribution of the residuals, linear association between outcome and exposures and homogeneity of the variance - were confirmed by visual inspection of the graphs.

The Ethics Committee of the Medical School at the Universidade Federal de Pelotas [Federal University in Pelotas], affiliated with the National Research Council, gave ethical approval for all phases of the 1993 Pelotas Birth Cohort Study. Written informed consent was obtained from the mothers or guardians of the cohort members.

\section{Results}

There were 5,265 live births in Pelotas in 1993. Of these, 5,249 were enrolled in our birth cohort study. In 2004-2005, 4,452 cohort members were traced. Added to the 141 subjects who are known to have died, they represent a follow-up rate of $87.5 \%$. Mean age in the 2004-2005 fol- 
low-up visit was 11.3 ( $\mathrm{SD}=0.3$ ) years. Subjects located in 2004-2005 had a mean birth length of $48.8 \mathrm{~cm}$ ( $S D=2.3$ ), while those who were lost to follow-up had a mean of $48.5 \mathrm{~cm}(\mathrm{SD}=2.8$; $\mathrm{p}=0.002$ ). Mean birthweight values were, respectively $3,175 \mathrm{~g}(\mathrm{SD}=522)$ and $3,050 \mathrm{~g}(\mathrm{SD}=676$; $\mathrm{p}<0.001)$. Nearly a fourth $(23.5 \%)$ of those located were small for gestational age. At 11 years, mean height was $145.8 \mathrm{~cm}(\mathrm{SD}=7.9)$ in the whole sample, with $144.9 \mathrm{~cm}(\mathrm{SD}=7.7)$ for boys and $146.8 \mathrm{~cm}$ $(\mathrm{SD}=7.9)$ for girls.

Table 1 describes the sample visited at 11 years in terms of perinatal and current variables. The results are stratified by birthweight for gestational age (small or adequate). Small for gestational age was significantly associated ( $\mathrm{p}<0.05$ ) with low income, poor maternal education, young maternal age, smoking during pregnancy, and lower maternal weight and height. AGA children were $3.4 \mathrm{~kg}$ heavier and $3.3 \mathrm{~cm}$ taller than those born SGA.

The Pearson correlation coefficient was calculated between perinatal (birthweight and length) and current (weight and height) anthropometric variables. All correlations were positive and significant (all $\mathrm{p}$ values $<0.001$ ). Current height presented a 0.24 correlation with birthweight, 0.25 with birth length, and 0.70 with current weight. Birthweight and birth length presented a correlation of 0.76 .

Table 2 shows that height at 11 years was positively associated with both birthweight and birth length. Comparing the extreme groups of birthweight, a difference of $9.0 \mathrm{~cm}$ in terms of height at 11 years was detected. In terms of birth length, the equivalent difference was $7.3 \mathrm{~cm}$.

Figure 1 shows two separate regression models using height at 11 years as the outcome and birthweight as the independent variable: one for SGA and another for AGA children The association between height and birthweight was positive in both groups, and apparently stronger for AGA than for SGA children. However, the p value for interaction was 0.56 . Figure 2 shows the same analyses for birth length. Again, a direct association was observed in both groups, but it was significantly stronger for AGA children ( $p$ for interaction equal to 0.001 ).

Table 3 presents results of the crude and multivariable analyses. Birthweight and birth length (z-scores) were treated as continuous variables. The crude positive effect of birthweight on height at 11 years became smaller but remained statistically significant after adjustment for confounding perinatal variables (model 1). This association was no longer significant after inclusion of birth length in the model. In terms of birth length, positive associations were found regardless of the model, although the magnitude of the association was slightly reduced after adjusting for confounders. These results were consistent for AGA and SGA children, although the magnitude of the association between birth length and height at 11 years was twice as high in AGA children. Based on model 2 results, a one $\mathrm{z}$-score increase in birth length is associated with a $1.63 \mathrm{~cm}$ increase in height at 11 years $(2.07 \mathrm{~cm}$ for AGA and $1.15 \mathrm{~cm}$ for SGA children).

Because pubertal stage is associated both with birth size 21 and with height in early adolescence, we tested whether the association between birth length and height persisted after adjustment for age at menarche. The unadjusted regression coefficient was 0.84 (95\%CI: 0.70; 0.99). After adjustment for age at menarche, it was virtually unchanged (regression coefficient $0.84,95 \% \mathrm{CI}$ : $0.71 ; 0.97)$.

\section{Discussion}

A positive association between birth length and height in early adolescence was found in this prospective birth cohort study including almost 4,500 Brazilian adolescents. A similar effect was observed for birthweight in the crude analysis, but adjustment for birth length removed the effect of birthweight on height in early adolescence. Sorensen et al. observed similar results in a study of Danish adults 12, in which both birth length and weight presented positive associations with later height, but after adjustment for one another, the effect of length was much more marked than that of weight.

Koziel \& Jankowska 11 observed an effect of birthweight on height at 14 years, but no adjustment was made for birth length. Their findings are similar to our crude results. Also consistent with our results is their finding that SGA children presented lower height in adolescence than AGA children. In a Brazilian study of children aged 1259 months, Drachler et al. 10 reported that birthweight was a strong predictor of stature, but this finding is not directly comparable to ours due to different age range and lack of adjustment for birth length. In short, our analyses are consistent with studies conducted in different settings, showing a crude association between height and both birth weight and length, and also suggesting a stronger role for birth length. A previous Brazilian study using data from the Ribeirão Preto cohort 22 also showed that the effect of birth length on later height is stronger than the effect of birth weight.

An interesting finding of our study, that we were unable to find in the published literature, 
Table 1

Description of the sample visited in 2004-2005 according to perinatal and current variables, stratified by birthweight for gestational age.

\begin{tabular}{|c|c|c|c|}
\hline Variables & $\begin{array}{c}\text { Overall } \\
\text { n (\%) }\end{array}$ & $\begin{array}{l}\text { AGA } \\
n(\%)\end{array}$ & $\begin{array}{l}\text { SGA } \\
n(\%)\end{array}$ \\
\hline \multicolumn{4}{|l|}{ Sex } \\
\hline Male & $2,166(48.7)$ & $1,503(49.3)$ & $441(47.1)$ \\
\hline Female & $2,285(51.3)$ & $1,543(50.7)$ & $496(52.9)$ \\
\hline \multicolumn{4}{|c|}{ Family income in 1993 (minimum wages) * } \\
\hline$\leq 1.0$ & $814(18.3)$ & $503(16.5)$ & $197(21.0)$ \\
\hline $1.1-3.0$ & $1,932(43.4)$ & $1,265(41.5)$ & $437(46.6)$ \\
\hline $3.1-6.0$ & $1,052(23.6)$ & $765(25.1)$ & $201(21.5)$ \\
\hline $6.1-10.0$ & $339(7.6)$ & $257(8.4)$ & $59(6.3)$ \\
\hline$>10.0$ & $315(7.1)$ & $256(8.4)$ & $43(4.6)$ \\
\hline \multicolumn{4}{|c|}{ Maternal schooling in 1993 (years) * } \\
\hline 0 & $105(2.4)$ & $59(1.9)$ & $11(1.2)$ \\
\hline $1-4$ & $1,132(25.4)$ & $708(23.2)$ & $278(29.7)$ \\
\hline $5-8$ & $2,126(47.8)$ & $1,449(47.6)$ & $456(48.8)$ \\
\hline$\geq 9$ & $1,086(24.4)$ & $830(27.3)$ & $190(20.3)$ \\
\hline \multicolumn{4}{|c|}{ Maternal age at delivery (years) * } \\
\hline$<20$ & $779(17.5)$ & $488(16.0)$ & $200(21.3)$ \\
\hline $20-34$ & $3,180(71.4)$ & $2,199(72.2)$ & 649 (69.3) \\
\hline$\geq 35$ & $492(11.1)$ & $359(11.8)$ & $88(9.4)$ \\
\hline \multicolumn{4}{|c|}{ Maternal smoking during pregnancy * } \\
\hline No & $2,960(66.5)$ & $2,140(70.3)$ & $531(56.7)$ \\
\hline Yes & $1,492(33.5)$ & $906(29.7)$ & $406(43.3)$ \\
\hline \multicolumn{4}{|c|}{ Maternal weight $(\mathrm{kg})$ * } \\
\hline$<60$ & $2,709(62.0)$ & $11,745(57.9)$ & $675(73.1)$ \\
\hline$\geq 60$ & $1,663(38.0)$ & $1,271(42.1)$ & $248(26.9)$ \\
\hline \multicolumn{4}{|c|}{ Maternal height $(\mathrm{cm})$ * } \\
\hline$<160$ & $2,110(47.8)$ & $1,304(43.0)$ & $535(57.8)$ \\
\hline$\geq 160$ & $2,308(52.2)$ & $1,726(57.0)$ & $390(42.2)$ \\
\hline \multicolumn{4}{|l|}{ Birthweight $(g)$ * } \\
\hline$<1,500$ & $13(0.3)$ & $2(0.1)$ & $8(0.9)$ \\
\hline $1,500-2,499$ & $386(8.7)$ & $105(3.5)$ & $210(22.4)$ \\
\hline $2,500-3,499$ & $2,866(64.5)$ & $1,862(61.1)$ & $719(76.7)$ \\
\hline $3,500-4,499$ & $1,141(25.7)$ & $1,039(34.1)$ & $0(0.0)$ \\
\hline$\geq 4,500$ & $39(0.8)$ & $38(1.3)$ & $0(0.0)$ \\
\hline \multicolumn{4}{|c|}{ Birth length $(\mathrm{cm})$ * } \\
\hline$<45.0$ & $168(3.8)$ & $62(2.1)$ & $76(8.2)$ \\
\hline $45.0-46.9$ & $480(10.9)$ & $195(6.5)$ & $219(23.6)$ \\
\hline $47.0-48.9$ & $1,236(28.0)$ & $690(22.8)$ & $407(43.9)$ \\
\hline $49.0-50.0$ & $1,676(38.0)$ & $1,309(43.3)$ & $208(22.4)$ \\
\hline$\geq 51$ & $851(19.3)$ & $769(25.4)$ & $17(1.8)$ \\
\hline \multicolumn{4}{|c|}{ Weight at $10-12$ years $(\mathrm{kg})$ * } \\
\hline$<30$ & $624(14.1)$ & $339(11.2)$ & $202(21.6)$ \\
\hline $30-39.9$ & $1,997(45.0)$ & $1,327(43.7)$ & $444(47.4)$ \\
\hline $40-49.9$ & $1,140(25.7)$ & $845(27.8)$ & $187(20.0)$ \\
\hline$\geq 50$ & $681(15.3)$ & $529(17.4)$ & $103(11.0)$ \\
\hline \multicolumn{4}{|c|}{ Height at 10-12 years $(\mathrm{cm})$ * } \\
\hline$<140$ & $1,005(22.6)$ & $556(18.3)$ & $308(32.9)$ \\
\hline $140-149.9$ & $2,094(47.1)$ & $1,458(48.0)$ & $424(45.3)$ \\
\hline $150-159.9$ & $1,168(26.3)$ & $871(28.7)$ & $189(20.2)$ \\
\hline$\geq 160$ & $175(3.9)$ & $155(5.1)$ & $15(1.6)$ \\
\hline
\end{tabular}

AGA: adequate for gestational age; SGA: small for gestational age.

* Differences significant at the 0.05 level. 
Mean (standard deviation - SD) height at 11 years according to birthweight and birth length categories.

\begin{tabular}{lll}
\hline Variable & Mean (SD) height at 10-12 years (cm) & $<0.001$ \\
\hline Birthweight (g) & & \\
$<1,500$ & $141.0(6.3)$ & $142.6(8.3)$ \\
1,500-2,499 & $145.3(7.7)$ & $<0.001$ \\
$2,500-3,499$ & $148.2(7.5)$ \\
3,500-4,499 & $150.0(8.5)$ \\
$\geq 4,500$ & \\
Birth length (cm) & $142.2(8.0)$ \\
$<45.0$ & $143.5(7.5)$ \\
$45.0-46.9$ & $144.3(7.6)$ \\
$47.0-48.9$ & $146.2(7.5)$ \\
$49.0-50.0$ & $149.5(7.7)$ \\
\hline 51 &
\end{tabular}

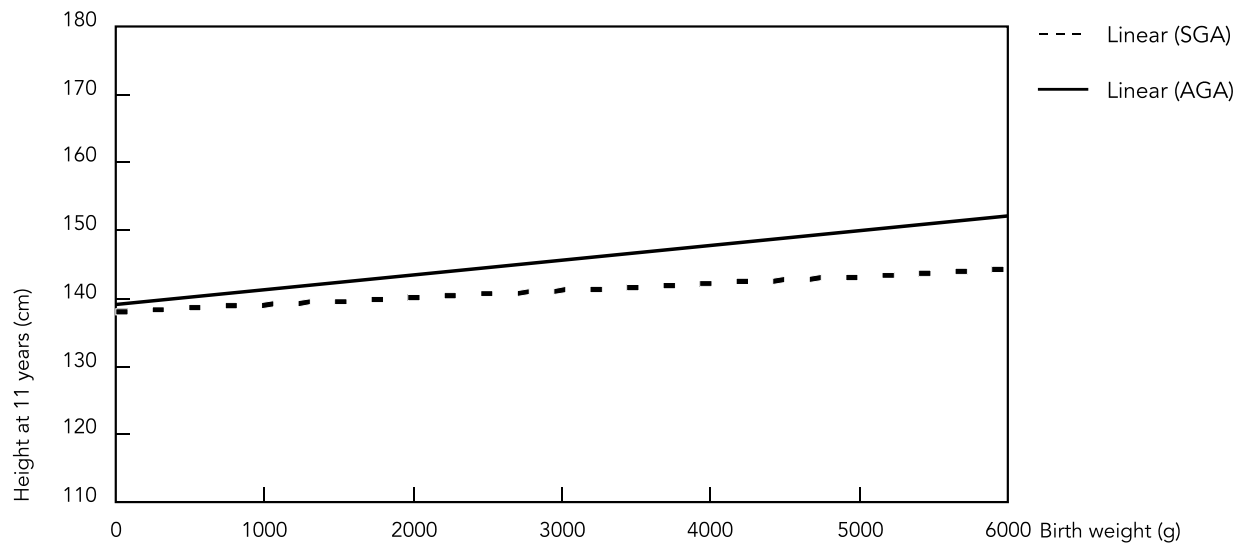

$p$ value for interaction $=0.56$

was documentation of a stronger effect of size at birth on later height among AGA than SGA children. One may speculate whether the adverse social and environmental conditions faced by SGA children - both in utero and probably persisting after birth - may somehow contribute to weakening the expected association between birth size and later height. Data from Table 1 confirm that SGA and AGA children differ in various aspects: mothers are poorer, younger, less educated, more likely to smoke during pregnancy, shorter, and thinner. Family income is also lower among SGA children in comparison to AGA ones.

The study limitations include not being able to trace $12 \%$ of the original sample and lack of information on paternal height, a variable that was difficult to collect because many of the fathers were not available during the interview. The overall follow-up rate $(87.5 \%)$ can be considered excellent in comparison to other cohort 
Linear regression between birthweight and height at 11 years among small (SGA) and adequate for gestational age (AGA) children.

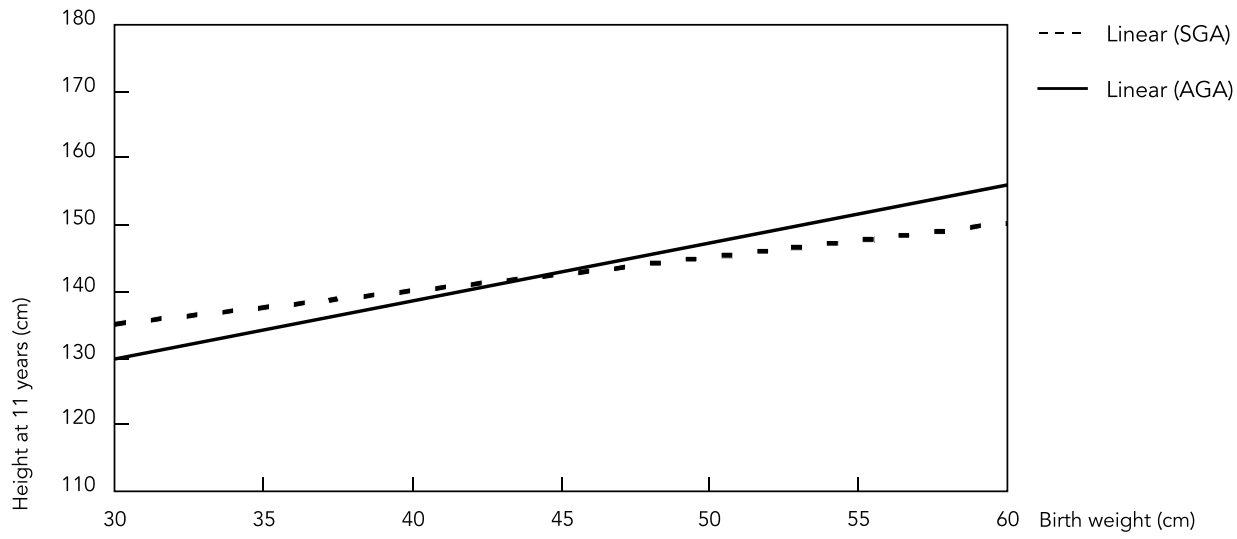

$\mathrm{p}$ value for interaction $<0.001$

Table 3

Effect of perinatal variables on height at 11 years; crude and multivariable analysis.

\begin{tabular}{|c|c|c|c|}
\hline \multirow[t]{2}{*}{ Variable } & \multicolumn{3}{|c|}{ Linear regression coefficients $(95 \% \mathrm{Cl})$} \\
\hline & Crude analysis & Model 1 & Model 2 \\
\hline \multicolumn{4}{|l|}{ All children } \\
\hline \multirow[t]{2}{*}{ Birthweight (z-score) } & $2.06(1.82 ; 2.29)$ & $1.42(1.18 ; 1.65)$ & $0.25(-0.10 ; 0.60)$ \\
\hline & $p<0.001$ & $p<0.001$ & $p=0.16$ \\
\hline \multirow[t]{2}{*}{ Birth length (z-score) } & $2.40(2.15 ; 2.67)$ & $1.81(1.57 ; 2.06)$ & $1.63(1.27 ; 1.99)$ \\
\hline & $p<0.001$ & $p<0.001$ & $p<0.001$ \\
\hline \multicolumn{4}{|l|}{ AGA children } \\
\hline \multirow[t]{2}{*}{ Birthweight (z-score) } & $1.84(1.53 ; 2.16)$ & $1.31(1.00 ; 1.62)$ & $-0.04(-0.47 ; 0.40)$ \\
\hline & $p<0.001$ & $p<0.001$ & $p=0.87$ \\
\hline \multirow[t]{2}{*}{ Birth length (z-score) } & $2.51(2.18 ; 2.84)$ & $2.04(1.72 ; 2.37)$ & $2.07(1.62 ; 2.51)$ \\
\hline & $p<0.001$ & $p<0.001$ & $p<0.001$ \\
\hline \multicolumn{4}{|l|}{ SGA children } \\
\hline \multirow[t]{2}{*}{ Birthweight (z-score) } & $1.56(0.60 ; 2.51)$ & $1.14(0.22 ; 2.07)$ & $-0.33(-1.65 ; 0.99)$ \\
\hline & $p=0.001$ & $p=0.02$ & $p=0.63$ \\
\hline \multirow[t]{2}{*}{ Birth length (z-score) } & $1.31(0.68 ; 1.94)$ & $1.02(0.41 ; 1.62)$ & $1.15(0.33 ; 1.97)$ \\
\hline & $p<0.001$ & $p<0.001$ & $p=0.006$ \\
\hline
\end{tabular}

Model 1: adjusted for maternal weight and height at the beginning of the pregnancy, family income, maternal smoking during pregnancy, parity, maternal schooling, maternal age, and child's sex; model 2: adjusted for model 1 variables plus perinatal anthropometric variables (birthweight adjusted for birth length and vice-versa); AGA: adequate for gestational age; SGA: small for gestational age. 
studies that also need to actively search for participants. Although mean birth weight and length were significantly different between those traced at 11 years and those not traced, the magnitude of the differences is not large. Maternal height was measured, and its inclusion in the analyses helps to at least partially adjust for the effect of genetic conditions on adolescent height 23 . An important variable to adjust for is pubertal stage. Among girls, we were able to collect data on age at menarche, and our results did not change after adjusting for this variable. Therefore, we do not believe our findings are confounded by pubertal stage.

Birth length has received considerably less attention than birthweight in the literature, possibly because it is measured less often, and - even when it is - more difficult to assess precisely. Further studies are required comparing the longterm consequences of being short at birth.

\section{Resumo}

O objetivo deste estudo foi avaliar a associação entre o tamanho ao nascer (peso e comprimento) e altura no início da adolescência em uma coorte de nascimentos prospectiva em Pelotas, Rio Grande do Sul, Brasil. Entrevistas foram conduzidas em 1993, incluindo mensuração de peso e comprimento ao nascer, e em 2004-2005, incluindo mensuração de peso e altura. Esta análise inclui 4.452 indivíduos com idade média de 11,3 anos ( $D P=0,3)$, representando uma ta$x$ a de acompanhamento de $87,5 \%$. A média de altura aos 11 anos foi de $145,8 \mathrm{~cm}(D P=7,9)$, sendo $144,9 \mathrm{~cm}$ $(D P=7,7)$ entre os meninos e $146,8 \mathrm{~cm}(D P=7,9)$ entre as meninas. O peso e o comprimento ao nascer associaram-se positivamente com a altura no início da adolescência na análise bruta, mas após ajuste para fatores de confusão e um para o outro, apenas o efeito do comprimento continuou significativo. Um aumento de um escore- $z$ no comprimento ao nascer esteve associado com um aumento de 1,63cm na altura aos 11 anos. O estudo mostra que o comprimento ao nascer é um forte preditor da altura futura, enquanto o efeito do peso ao nascer desaparece após ajuste para o comprimento ao nascer.

Estatura; Peso ao Nascer; Idade Gestacional; Estudos Prospectivos; Estudos Longitudinais

\section{Contributors}

C. L. P. Araújo had the original idea and coordinated the writing process. P. C. Hallal led data analyses. G. A. Nader conducted the literature review and coordinated the fieldwork. C. L. P. Araújo and A. M. B. Menezes are the coordinators of the 2004-2005 follow-up visit of the 1993 Pelotas (Rio Grande do Sul, Brazil) Birth Cohort Study. C. G. Victora is the coordinator of the overall project. All authors took part in the writing process and approved the final version of the manuscript.

\section{Acknowledgments}

This analysis was supported by the Wellcome Trust's initiative entitled Major Awards for Latin America on Health Consequences of Population Change. Earlier phases of the 1993 cohort study were funded by the European Union, the National Program for Centers of Excellence (Brazil), the National Research Council (Brazil), and the Ministry of Health (Brazil). 


\section{References}

1. Leitch I. Growth and health. Int J Epidemiol 2001; 30:212-6.

2. Ruel MT. The natural history of growth failure: importance of intrauterine and postnatal periods. In: Martorell R, Hasschke F, editors. Nutrition and growth. Lippincott: Williams \& Wilkins; 2001.p. 123-57. (Nestlé Nutrition Workshop Series, Pediatric Program v. 47).

3. Batista Filho M, Rissin A. A transição nutricional no Brasil: tendências regionais e temporais. Cad. Saúde Pública 2003; 19 Suppl 1:S181-91.

4. Waaler HT. Height, weight and mortality. The Norwegian experience. Acta Med Scand Suppl 1984; 679:1-56.

5. Peck ANM, Vagero D. Adult body height, selfperceived health and mortality in the Swedish population. J Epidemiol Community Health 1989; 43:380-4.

6. Allbeck P, Bergh C. Height, body mass and mortality: do social factors explain the association? Public Health 1992; 106:375-82.

7. Post CL, Victora CG, Barros FC, Horta BL, Guimarães PRV. Desnutrição e obesidade infantis em duas coortes de base populacional no Sul do Brasil: tendências e diferenciais. Cad Saude Publica 1996; 12 Suppl 1:S49-57.

8. United Nations System/Standing Committee on Nutrition (SCN). 5th Report on the World Nutrition Situation. Nutrition for improved development outcomes: nutrition trends and implications for attaining the MDGs. Geneva: World Health Organization; 2004.

9. Gigante DP, Victora CG, Araújo CLP, Barros FC. Tendências no perfil nutricional das crianças nascidas em 1993 em Pelotas, Rio Grande do Sul, Brasil: análises longitudinais. Cad Saúde Pública 2003; 19 Suppl 1:S141-7.

10. Drachler ML, Andersson MCS, Leite JCC, Marshall T, Aerts DRGC, Freitas PF, et al. Desigualdade social e outros determinantes da altura em crianças: uma análise multinível. Cad Saúde Pública 2003; 19:1815-25.

11. Koziel S, Jankowska EA. Birthweight and stature, body mass index and fat distribution of 14-yearold Polish adolescents. J Paediatr Child Health 2002; 38:55-8.

12. Sorensen HT, Sabroe S, Rothman KJ, Gillman M, Steffensen FH, Fischer P, et al. Birth weight and length as predictors for adult height. Am J Epidemiol 1999; 149:726-9.
13. Wells JCK, Hallal PC, Wright A, Singhal A, Victora CG. Fetal, infant and childhood growth: relationships with body composition in Brazilian boys aged 9 years. Int J Obes 2005; 29:1192-8.

14. Gigante DP, Horta BL, Lima RC, Barros FC, Victora CG. Early life factors are determinants of female height at age 19 years in a population-based birth cohort (Pelotas, Brazil). J Nutr 2006; 136:473-8.

15. Barros FC, Victora CG, Barros AJD, Santos IS, Albernaz E, Matijasevich A, et al. The challenge of reducing neonatal mortality in middle-income countries: findings from three Brazilian birth cohorts, 1982-1993-2004. Lancet 2005; 365:847-54.

16. Dubowitz LM, Dubowitz V, Goldberg C. Clinical assessment of gestational age in the newborn infant. J Pediatr 1970; 77:1-10.

17. Centers for Disease Control and Prevention. CDC Growth charts: United States http://www.cdc. gov/nchs/about/major/nhanes/growthcharts/ background.htm 2000 (accessed on 23/Feb/2006).

18. Kramer MS, Platt RW, Wen SW, Joseph KS, Allen A, Abrahamowiczs M, et al. A new and improved population-based Canadian reference for birth weight for gestational age. Pediatrics 2001; 108:e35.

19. Victora CG, Araújo CLP, Menezes AMB, Hallal PC, Vieira MF, Neutzling MB, et al. Methodological aspects of the 1993 Pelotas (Brazil) Birth Cohort Study. Rev Saúde Pública 2006; 40:39-46.

20. Cameron N. Reliability. In: Cameron N, editor. The measurement of human growth. London: Croom Helm; 1984. p. 100-12.

21. Silva IS, De Stavola BL, Mann V, Kuh D, Hardy R, Wadsworth MEJ. Prenatal factors, childhood growth trajectories and age at menarche. Int J Epidemiol 2002; 31:405-12.

22. Haeffner LS, Barbieri MA, Rona RJ, Bettiol H, Silva AA. The relative strength of weight and length at birth in contrast to social factors as determinants of height at 18 years in Brazil. Ann Hum Biol 2002; 29:627-40.

23. Eveleth PB, Tanner JM. Worldwide Variation in Human Growth. 2nd Ed. Cambridge: Cambridge University Press; 1990.

Submitted on $01 / \mathrm{Feb} / 2006$

Final version resubmitted on 21/May/2007

Approved on 28/May/2007 